\title{
ОБ ОЦЕНКЕ ЭФФЕКТИВНОСТИ СТРАТЕГИЧЕСКОГО ПЛАНИРОВАНИЯ В СФЕРЕ АЛЬТЕРНАТИВНОЙ ЭНЕРГЕТИКИ В РОССИЙСКОЙ ФЕДЕРАЦИИ
}

\author{
(C) 2021 Ахметшина Алсу Ринатовна \\ доктор экономических наук, профессор, директор Высшей школы бизнеса \\ Казанский (Приволжский) федеральный университет, Россия, Татарстан, Казань \\ E-mail: mbakazan@kpfu.ru \\ (C) 2021 Салихов Ирек Фаритович \\ кандидат экономических наук, доцент, председатель Совета директоров АО «ЯДРАН» \\ Высшая школа бизнеса \\ Казанский (Приволжский) федеральный университет, Россия, Татарстан, Казань \\ E-mail: mbakazan@kpfu.ru
}

В статье авторов затрагиваются вопросы оценки эффективности стратегического планирования в сфере альтернативной энергетики в Российской Федерации. Обозначенным объектом исследования выступает сфера альтернативной энергетики в Российской Федерации, а предметом - эффективность стратегического планирования в ней. Теоретическое значение исследования проявляется через формирование авторской интерпретации критериального подхода (включающего разработку специализированного набора критериев), примененного для оценки эффективности стратегического планирования в сфере альтернативной энергетики. Прикладное и практическое значение исследования берут начало при формировании комплекса рекомендаций, пригодных для использования в Российской Федерации для повышения эффективности стратегического планирования в обозначенной сфере. Практические результаты, формализованные посредством изложения предложенных авторами разработок, могут быть использованы в процессе анализа и формирования оптимизационных мероприятий обширного перечня научных задач в плоскости энергетики, менеджмента и экономики.

Ключевые слова: стратегическое планирование, стратегия, альтернативная энергетика, Российская Федерация, эффективность, сфера, инициатива.

Сфера стратегического планирования в современных условиях развития человечества без преувеличения является одной из самых значимых в процессе формирования новейшей истории [7], так как именно от ее эффективности зависит эффективность функционирования всех без исключения систем международных формаций (от финансовых и экономических до энергетических).

Естественно, что указанная закономерность без каких-либо значимых допущений проявляется и в разрезе отдельно взятых стран, включая Российскую Федерацию.

Рассматривая данный вопрос здесь более детально, можно прийти к выводу, что система стратегического планирования в Российской Федерации достаточно тесно интегрирована в процесс управления на федеральном уровне и включает в себя множество отдельно взятых сфер, таких как социум, производство, энергетика $[4$, с. 291] и другие.

Стратегическое планирование в рамках ка- ждой из обозначенных сфер имеет свою специфику, выраженную набором персональных особенностей, учитывающих так или иначе текущее состояние системы по совокупности внешних и внутренних факторов.

Исходя из того, что в условиях глобального перехода всех стран на безуглеродный путь развития особую значимость приобретает альтернативная энергетика (основанная в первую очередь на возобновляемых источниках энергии [5, c. 139]), в рамках данной публикации была выделена и проанализирована именно данная часть энергетической сферы Российской Федерации в актуальный временной интервал.

По итогам 2020 года альтернативная энергетика в Российской Федерации (аспект генерации, ТВт-час) была представлена следующими основными возобновляемыми источниками (ВИЭ), данные по которым отражены на рисунке 1.

Из рисунка 1 видно, что совокупный объем производства энергии из возобновляемых источников за анализируемый период времени 


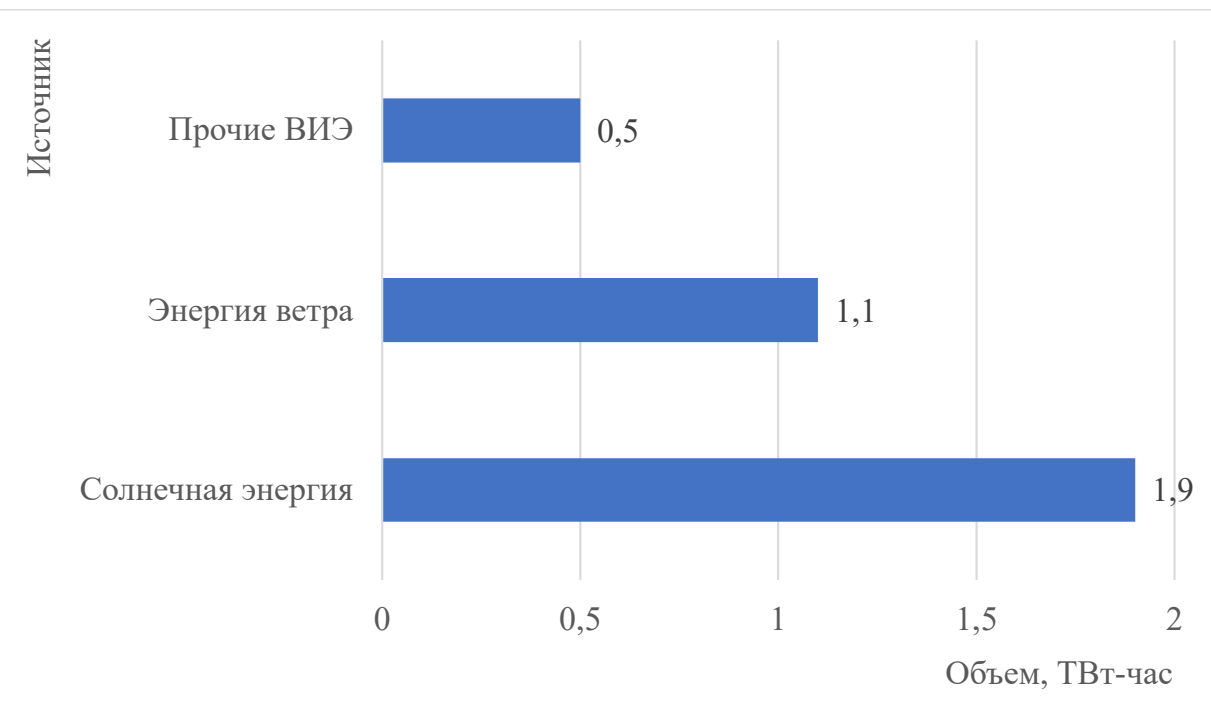

Puc. 1. Данные по производству энергии в рамках основных возобновляемых источников в Российской Федерации в 2020 году, ТВт-час [6]

составил 3,5 ТВт-часов. При этом основными источниками здесь являлись:

- солнечная энергия (доля в совокупном объеме генерации за 2020 год составила 54,28 процента или 1,9 ТВт-часов);

- энергия ветра (доля в совокупном объеме генерации за 2020 год составила 31,43 процента или 1,1 ТВТ-часов).

Если учесть, что мировой объем генерации энергии из возобновляемых источников за исследуемый период времени составил 3147 ТВт-часов (то есть практически в 900 раз больше), значение показателя генерации для Российской Федерации выглядит более чем умеренно, обозначая тем самым огромные перспективы для стратегического роста.

Аналогичная картина имеет место и в инвестиционной проекции, структура которой в мировом масштабе в рамках возобновляемых источников энергии за 2020 год приведена на рисунке 2 .

Как можно увидеть из рисунка 2 , совокупный объем инвестиций в возобновляемые источники энергии в 2020 году составил 304 миллиарда долларов США.

Объем инвестиций Российской Федерации в данной сумме (входит в группу прочих развивающихся стран) не превышает 3 миллиардов долларов США, то есть более чем в 100 раз меньше. Это еще раз доказывает наличие возможности для значительного стратегического роста.

Было выяснено, что причин сложившейся ситуации достаточно много, но так или иначе значимая часть из них связана с несовершен- ством процесса стратегического планирования, приводящим к деструкции устойчивого развития [2, 3]. Исходя из этого, в рамках данного исследования была предпринята попытка проведения оценки эффективности обозначенного процесса в сфере альтернативной энергетики $[1,9]$ на предмет определения текущей ситуации и формирования понимания о его дальнейших стратегических перспективах в Российской Федерации.

Для проведения оценки эффективности стратегического планирования в сфере альтернативной энергетики в Российской Федерации был разработан авторский набор критериев (с возможностью их количественной оценки), учитывающий наиболее значимые аспекты текущей ситуации на рынке. Состав, характеристика и значимость данных критериев (в совокупности пять позиций) приведены в таблице 1.

По таблице 1 поясним следующее:

- наибольшую значимость из рассмотренных критериев имеют: уровень формализации процесса стратегического планирования (совокупная значимость 31,99 процента из 100 процентов) и уровень кадрового обеспечения процесса (совокупная значимость 27,18 процентов из 100 процентов);

- далее следуют: уровень методического обеспечения процесса (совокупная значимость 17,35 процентов из 100 процентов) и уровень информационного обеспечения процесса (совокупная значимость 12,31 процента из 100 процентов);

- наименее значимым (совокупная значимость чуть более 11 процентов) является кри- 


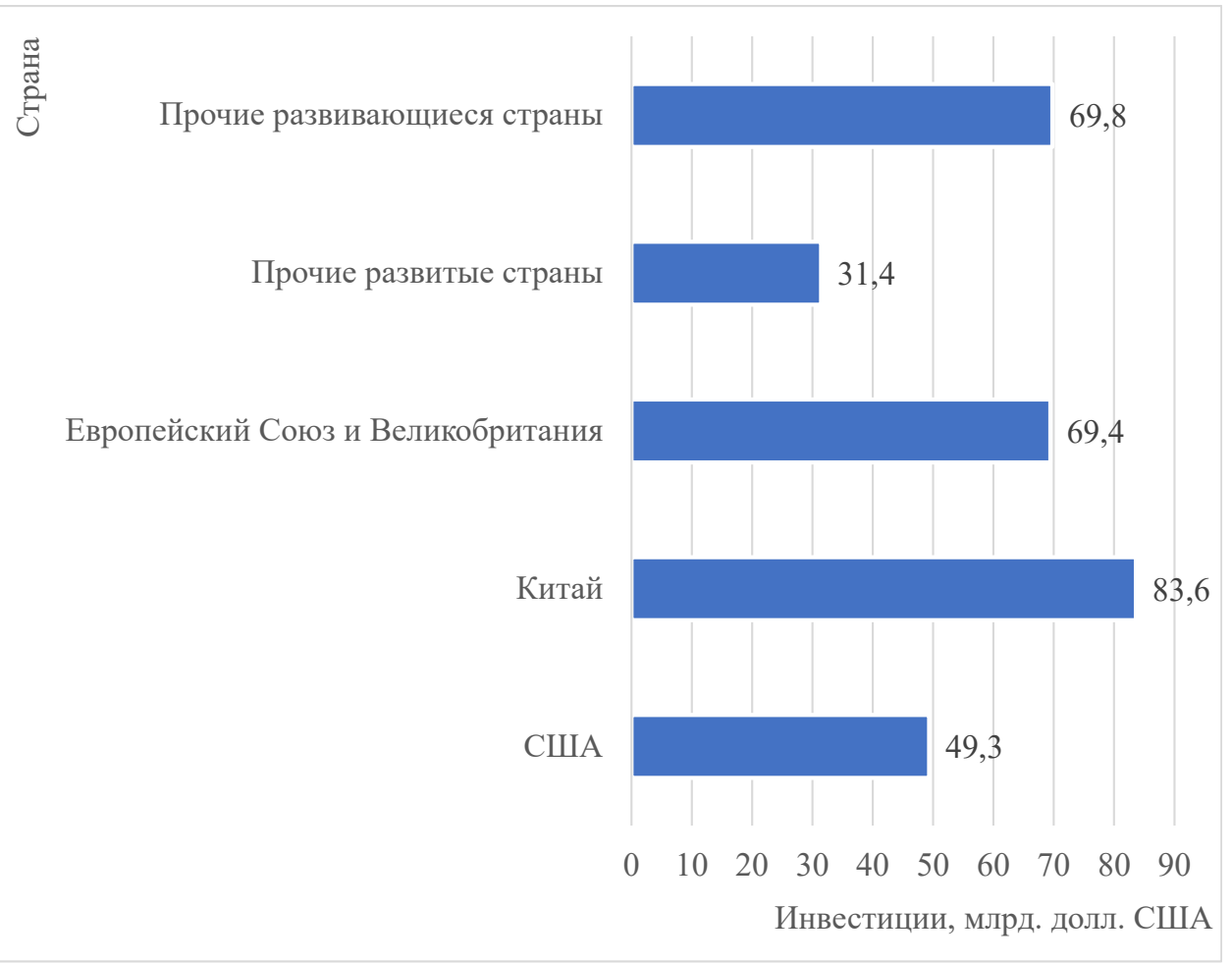

Puc. 2. Структура инвестиций в возобновляемые источники энергии в 2020 году в мировом масштабе, млрд. долл. США [8]

Таблица 1. Состав, характеристика и значимость критериев, пригодных для оценки эффективности стратегического планирования в сфере альтернативной энергетики в Российской Федерации

\begin{tabular}{|c|c|c|}
\hline Наименование критерия & $\begin{array}{c}\text { Характеристика } \\
\text { критерия }\end{array}$ & $\begin{array}{l}\text { Значимость } \\
\text { критерия,\% }\end{array}$ \\
\hline $\begin{array}{l}\text { Уровень формализации процесса стратеги- } \\
\text { ческого планирования }\end{array}$ & $\begin{array}{l}\text { Характеризует текущее положение страте- } \\
\text { гического планирования в анализируемой } \\
\text { сфере на предмет наличия самой стратегии } \\
\text { и ее отдельных компонентов }\end{array}$ & 31,99 \\
\hline Уровень кадрового обеспечения процесса & $\begin{array}{l}\text { Характеризует текущее положение страте- } \\
\text { гического планирования в анализируемой } \\
\text { сфере на предмет наличия эффективного } \\
\text { кадрового обеспечения }\end{array}$ & 27,18 \\
\hline $\begin{array}{l}\text { Уровень методического обеспечения про- } \\
\text { цесса }\end{array}$ & $\begin{array}{l}\text { Характеризует текущее положение страте- } \\
\text { гического планирования в анализируемой } \\
\text { сфере на предмет наличия эффективного } \\
\text { методического обеспечения }\end{array}$ & 17,35 \\
\hline $\begin{array}{l}\text { Уровень информационного обеспечения } \\
\text { процесса }\end{array}$ & $\begin{array}{l}\text { Характеризует текущее положение страте- } \\
\text { гического планирования в анализируемой } \\
\text { сфере на предмет наличия эффективного } \\
\text { информационного обеспечения }\end{array}$ & 12,31 \\
\hline $\begin{array}{l}\text { Уровень нормативно-правового обеспече- } \\
\text { ния процесса }\end{array}$ & $\begin{array}{l}\text { Характеризует текущее положение страте- } \\
\text { гического планирования в анализируемой } \\
\text { сфере на предмет наличия эффективного } \\
\text { законодательного (нормативно-правового) } \\
\text { обеспечения }\end{array}$ & 11,17 \\
\hline \multicolumn{2}{|c|}{ Итоговый уровень значимости } & 100,00 \\
\hline
\end{tabular}


терий, отражающий нормативно-правовое обеспечение процесса.

Локальное значение каждого критерия оценивается по бальной шкале от 0 до 10 баллов, где 0 - наихудшая оценка объекта по данному критерию, а 10 - наилучшая оценка объекта по данному критерию.

Результаты оценки эффективности стратегического планирования в сфере альтернативной энергетики в Российской Федерации на начало 2021 года, согласно разработанному перечню критериев, приведены в таблице 2 .

Основываясь на данных таблицы 2 можно сделать вывод, что совокупная значимая оценка разработанного набора критериев на начало 2021 года находится чуть ниже отметки в 5 баллов из 10 возможных. При этом наибольшие (исходя из оценочных значений критериев) проблемы в Российской Федерации имеют место в уровне формализации процесса стратегического планирования (оценка 2 балла из 10 возможных) и уровне методического обеспечения процесса (оценка 4 балла из 10 возможных).

Таким образом, по итогам проведенного исследования можно выделить следующие значимые моменты:

- система стратегического планирования является важнейшим компонентом развития любой без исключения современной страны в глобальном мировом пространстве;

- ориентация на безуглеродный путь развития глобального мирового пространства выделяет определенные акценты (например, в области альтернативной энергетики) в сферах стратегического планирования отдельно взятых стран, включая Российскую Федерацию;

- к сожалению значимость альтернативной энергетики Российской Федерации в мировом масштабе довольно незначительная, как по объему производства энергии из возобновляемых источников (соотношение объемов не менее чем 1 к 900), так и по объему финансирования данного сектора (соотношение объемов не менее чем 1 к 100);

- эффективность стратегического планирования в Российской Федерации на начало 2021 года, измеренная по разработанному набору критериев с переменным уровнем значимости, оценивается ниже средней и составляет 4,93 балла из 10 возможных;

- в целях изменения сложившейся ситуации в сфере альтернативной энергетики и повышения эффективности стратегического планирования в Российской Федерации предлагается:

a) формализовать процесс стратегического планирования за счет разработки стратегии развития альтернативной энергетики с горизонтами планирования три, пять и десять лет;

б) модернизировать (возможно, на основе изучения зарубежного опыта по данному вопросу) комплекс методического обеспечения анализируемого процесса по каждому источнику генерации;

в) актуализировать с учетом воздействия на глобальное общество мировой пандемии коронавируса и одновременно синхронизировать с методической составляющей нормативноправовое обеспечение процесса.

Таблица 2. Результаты оценки эффективности стратегического планирования в сфере альтернативной энергетики в Российской Федерации на начало 2021 года, согласно разработанному перечню критериев

\begin{tabular}{|l|c|c|c|}
\hline \multicolumn{1}{|c|}{\begin{tabular}{c}
\multicolumn{1}{|c|}{ Наименование } \\
критерия
\end{tabular}} & $\begin{array}{c}\text { Оценка критерия, } \\
\text { баллы }\end{array}$ & $\begin{array}{c}\text { Значимость крите- } \\
\text { рия,\% }\end{array}$ & $\begin{array}{c}\text { Значимая оценка кри- } \\
\text { терия, баллы }\end{array}$ \\
\hline $\begin{array}{l}\text { Уровень формализации процес- } \\
\text { са стратегического планирования } \\
(0-10)\end{array}$ & 2,00 & 31,99 & 0,64 \\
\hline $\begin{array}{l}\text { Уровень кадрового обеспечения про- } \\
\text { цесса (0-10) }\end{array}$ & 8,00 & 27,18 & 2,17 \\
\hline $\begin{array}{l}\text { Уровень методического обеспечения } \\
\text { процесса (0-10) }\end{array}$ & 4,00 & 17,35 & 0,69 \\
\hline $\begin{array}{l}\text { Уровень информационного обеспе- } \\
\text { чения процесса (0-10) }\end{array}$ & 7,00 & 12,31 & 0,86 \\
\hline $\begin{array}{l}\text { Уровень нормативно-правового обе- } \\
\text { спечения процесса (0-10) }\end{array}$ & 5,00 & 11,17 & 0,56 \\
\hline Итого & 26,00 & 100,00 & 4,93 \\
\hline
\end{tabular}




\section{Библиографический список}

1. Александров Ю.Л., Александров Ю.Д. Сравнительный анализ энергетических стратегий ЕС и России / Ю.Л.Александров, Ю.Д.Александров / Вопросы экономических наук - Москва: Изд-во: ООО «Издательство «Спутник+», 2021. - № 2. - С. 8-10.

2. Ахметшина А.P. Оценка уровня функционирования институциональной среды устойчивого развития в России / А. Р. Ахметшина / Управление устойчивым развитием - Казань: Изд-во: ФГБОУ ВПО «КНИТУ», 2021. № 4 (35). С. 5-10.

3. Ахметшина А.Р., Салихов И.Ф. Реализация концептуальных положений устойчивого развития на современных предприятиях: зарубежный опыт / А. Р. Ахметшина, И. Ф. Салихов / Вестник экономики, права и социологии - Казань: Изд-во: ООО «Эксперт 16», 2020. № 4. С. 15-17.

4. Хорошильцев М.И. Проблемные аспекты стратегического развития электроэнергетики РФ / М.И.Хорошильцев / Russian economic bulletin - Махачкала: Изд-во: «ИП Клюева М. М.», 2021. - № 1. - С. $291-297$.

5. Шмелева А. И., Конников Е.А. и др. Влияние развития информационных технологий на рынок возобновляемых источников энергии / А.И.Шмелева, Е.А. Конников, Д. А. Крыжко / Экономические науки - Москва: Изд-во: ООО «24 Принт», 2021. - № 7. - С. 139-148.

6. Компания «British Petroleum plс» [Электронный ресурс]: Statistical Review of World Energy 2021 - Официальный сайт компании «British Petroleum plc», 2021. - Режим доступа: https://www.bp.com/

7. Компания «Ernst\&Young» [Электронный ресурс]: обзоры информации для клиентов - Официальный сайт компании «Ernst\&Young», 2021. - Режим доступа: https://www.ey.com/ru_ru

8. Компания «REN21» [Электронный ресурс]: Renewables 2021 global status report - Официальный сайт компании «REN21», 2021. - Режим доступа: https://www.ren21.net/

9. Министерство энергетики Российской Федерации [Электронный ресурс]: Энергетическая стратегия Российской Федерации на период до 2035 года - Официальный сайт Министерства энергетики Российской Федерации, 2021. - Режим доступа: https://minenergo.gov.ru/node/1026 